\title{
Shakedown Analysis of Road Pavements - Application to Project Level and Network Level Scenarios
}

\author{
P. S. Ravindra
}

\begin{abstract}
Shakedown behaviour of road pavements was investigated in laboratory controlled conditions using the Sydney University Pavement Testing Facility. Wheel loads lower than the shakedown load generated low permanent deformations for a larger number of load cycles in comparison with high permanent deformations for a lower number of load cycles for wheel loads higher than the shakedown load. Computer software was developed to calculate the shakedown limit using elastic stress distributions calculated with Sydney University's FLEA (Finite Layer Elastic Analysis) program. Case studies of shakedown theory to solve project level construction issues and remaining service life calculations at the network level are presented.
\end{abstract}

Keywords: Shakedown, pavements, roads

\section{Introduction}

A typical pavement structure is usually designed for a 40 year design period and to carry more than 100 million standard axles during its service life in modern day pavement design standards. Some major arterials in the developing world are designed to carry more than 400 million standard axles to a shorter 20 year design period. Most of these heavily trafficked roads are increasingly funded by private sector investors on behalf of local Road Authorities and so the road owners are very keen to utilise the pavement materials to their maximum strength capacity.

Once open to traffic, any road pavement will gradually deteriorate throughout its design life reducing its serviceability due to the application of repeated traffic loading and other environmental factors. An analysis which pays attention to this long term incremental mode of failure is highly desirable.

\section{Background}

Many researchers have shown that a collapse load calculated according to limit analysis may not represent the failure criteria in the case of variable repeated loads. Grüning [3] and Bleich [2] proved the static shakedown theorem for a system of steel beams with "I" shaped cross sections. They pointed out that for the case where repeated loads acting upon a given structure vary over a wide range, not only a structure can fail due to low-cycle fatigue below the collapse load calculated from a mechanism of instantaneous collapse but also an accumulation of plastic deformation may occur making the structure unserviceable. Their work has been quoted by König [6] in his monograph on Shakedown of Elastic-Plastic Structures. Melan [8] presented a more general theorem for trusses and later extended it to the case of a continuum Melan [9].

Sharp and Booker [14] pioneered the application of shakedown theory for the analysis of pavement behaviour. They applied the linear programming technique adopted by Maier [7]. The failure criterion was MohrCoulomb and material properties were assumed to be linear elastic - perfectly plastic.

Hossain and $Y u$ [4] and $Y u$ and Hossain [21] proposed a lower bound approach using discontinuous stress fields. The Residual stress field was modelled using 3-noded triangles where stress discontinuities were allowed at the edges of each triangle. A Lower bound shakedown limit was obtained from a total stress field that satisfied the yield condition everywhere within the region. Shiau and $Y u$ [15] presented a general numerical formulation using finite elements for the both elastic stress field and residual stress field to perform shakedown load calculation based on Melan's lower bound approach.

Eng. (Dr.) P.S .Ravindra, B.Sc. Eng. (Peradeniya), M.Eng. (Moratuwa), PhD. (Sydney Uni.), MIE(Sri Lanka),

MIE(Aust)(NPER),MICE,RPEQ,CPEng,C.Eng Consultant Pavement Engineer 
In contrast to analytical and numerical work on shakedown analysis of road pavements, experimental work associated with road pavements and pavement materials are relatively recent. Werkmeister [19] used shakedown theory to characterize unbound granular material based on repeated load triaxial test results. She concluded that the effects of change in moisture content on the deformation behaviour of the unbound granular material and the shakedown limit was significant. Ravindra [12] carried out detailed laboratory experiments at the University of Sydney Pavement Testing Facility in Australia to examine the application of shakedown theory by means of measuring accumulated plastic deformation after applying traffic loads below and above the shakedown load.

In this paper it is intended to discuss the Sydney University pavement testing facility experiment, application of shakedown theory to solve project level pavement construction issues and at the network level to correlate with remaining service life of pavements.

\section{Sydney University Pavement Testing Facility}

\subsection{Introduction of Sydney University Pavement Test Facility}

The testing facility shown in Fig. 1 was initially developed by Wong and Small [20] in order to test model pavements and was modified in order to change the position of the tyre across the pavement randomly by Moghaddas-Nejad and Small [10]. The facility consists of four main structural components, namely, the test tank, the overhead track and the loading carriage. The support and guidance for the moving loading carriage is provided by the overhead rails. The test section of pavement is constructed inside the test tank and positioned below one of the straight sections of the overhead track. The test wheel runs on a plywood track when outside of the test section of pavement. A conductor rail system supplies power to the motor which drives the wheel. The wheel passes over the test section of pavement once during each revolution around the track and triggers a micro switch that starts a micro computer recording data. All subsurface settlements are measured by buried Perspex discs ( $30 \mathrm{~mm}$ diameter) that are connected to a wire that passes through the

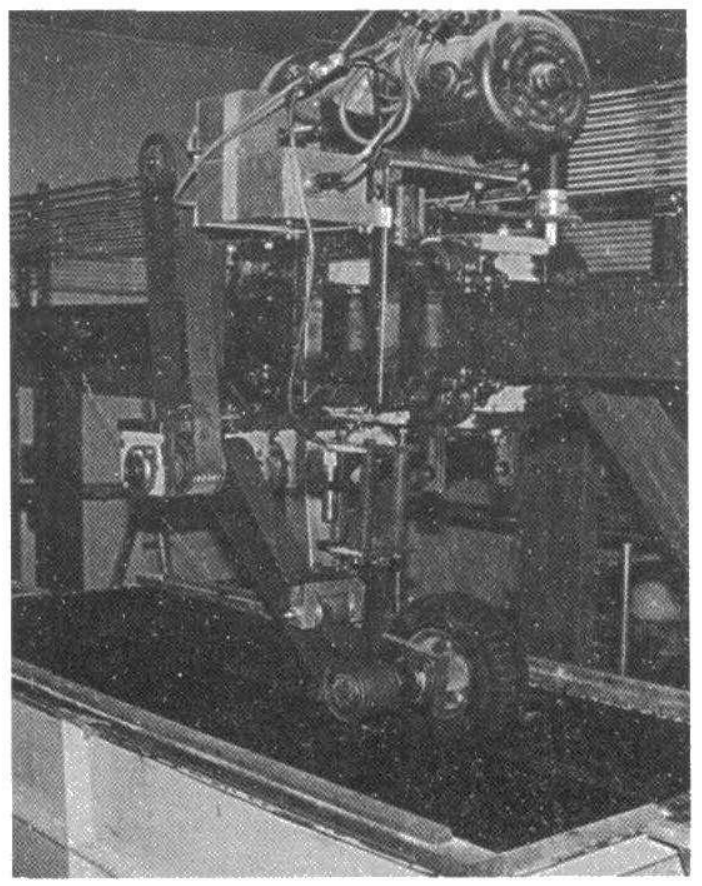

Figure 1- Spring Loading Arrangement and the Loading Wheel

base of the tank and are connected to individual Linear Voltage Differential Transducers (LVDTs). Data acquisition from each transducer output is carried out only during the passage of the wheel across the test section of pavement.

\subsection{Loading Wheel}

The loading wheel is supported by a rotating arm which is pivoted at the top by means of roller bearings. The position of the spring loading system is almost in the middle and the loading wheel is at the end of the horizontal portion of the rotating arm. By means of a hinged connection, the spring loading system is connected to the bottom bogie plate. To adjust the spring load on the rotating arm, a set of two adjusting nuts has been provided above and below the rotating arm so that compression in the springs can be changed by adjustment of the upper nut. Four identical springs with guide rods placed concentrically inside them make up the loading unit. To satisfy different loading requirements, springs with different stiffnesses can be set up in the system. An LVDT fitted between two reaction plates is used to monitor the variation of compression in 
the springs. There are two aluminium boxes supported by the bogie connection frame. The smaller box contains a power supply for the transducer and the larger one contains the analog to digital signal

converter, for transmission of data from the wheel carriage.

\subsection{Measurement of Surface Settlement}

In order to cater for the large number of cross section measurements envisaged in the project, a new laser distance measurement transducer based surface deformation, measurement system (Figure 3 ) was designed and developed to measure and record the surface deformations. With this new surface deformation measurement system, measuring of cross-sections was made easier and all measurements were recorded directly to a database.

\section{Pavement Tests}

The pavement tests conducted during the course of this experiment consisted of a sand subgrade and a recycled crushed concrete granular base layer. Base layer thickness was varied to select different pavement configurations.

\subsection{Sand Subgrade}

The grading of the sand used for the subgrade in the tests is given in Table 1 below:

Table 1. Particle Size Distribution of Loose Silica Sand (Test Specification AS 1289 3.6.1)

\begin{tabular}{|l|l|l|l|l|l|l|c|}
\hline $\begin{array}{l}\text { Sieve } \\
\text { size }\end{array}$ & 4.7 & 2.3 & 1.1 & 0.60 & 0.42 & 0.3 & 0.1 \\
\hline $\begin{array}{l}\mathrm{x} \\
\text { Pass. }\end{array}$ & 100 & 99 & 99 & 98 & 89 & 54 & 2 \\
\hline
\end{tabular}

\subsection{Base Material}

Base material used in the experiment was made up of recycled crushed concrete aggregate obtained from the Randwick Yarra Bay Material stockpile site. This material mainly consisted of crushed concrete obtained from council building demolition sites. This material was used as a base material in road rehabilitation works in the City Council area and was found to be easy to handle at the site with respect to compaction and spreading.
All material tests carried out were compared with current AUSPEC specifications and relevant ARIRB (Australian Road Research Board) recommended specifications for recycled crushed concrete. Direct Shear Box tests and Texas Triaxial tests were carried out to determine the angle of internal friction and cohesion values and values are given in Table 2 , while its grading is shown in Table 3 .

Table 2 Soil Strength Results for base Material

\begin{tabular}{|c|c|}
\hline Texas Triaxial & Direct Shear Box \\
$\phi=46^{\circ}$ & $\phi=51^{\circ}$ \\
$c=45 \mathrm{kPa}$ & $\mathrm{c}=56 \mathrm{kPa}$ \\
\hline
\end{tabular}

Table 3 Particle Size distribution for Recycled base

\begin{tabular}{|c|c|c|c|c|c|c|c|}
\hline $\begin{array}{l}\text { Sieve size } \\
(\mathrm{mm})\end{array}$ & 37.5 & 19 & 13.2 & 9.5 & 6.7 & 4.75 & 2.36 \\
\hline \%Passing & 100 & 93 & 77 & 65 & 58 & 51 & 44 \\
\hline $\begin{array}{l}\text { Sieve } \\
(\mathrm{mm})\end{array}$ & 1.18 & 0.600 & 0.425 & & 300 & 0.15 & \\
\hline$\%$ Passing & 38 & 32 & 27 & 6 & & 4 & \\
\hline
\end{tabular}

\subsection{Construction of Pavement}

A Standard Proctor hammer was used to compact the pavement layers. Moisture content was maintained at $O M C$ and the number of blows applied was evenly spread across the layer and were selected so as to give the same energy level to the base material as in the Standard Compaction Test. The pavement surface was allowed to dry at $20^{\circ} \mathrm{C}$ room temperature before lightly brushing off the loose fines in order to apply the bitumen emulsion seal coat with $5 \mathrm{~mm}$ single sized cover aggregate. Emulsion was applied with a roller brush and spread evenly across the pavement. After application of the cover aggregate, a light compaction pass was applied to embed the cover aggregate into the emulsion layer as a single layer of thickness equal to the aggregate's least dimension. A further 24 to 48 hours drying period was allowed before brushing the loose cover aggregate off the surface. Wheel entry and exit sections were kept at $350 \mathrm{~mm}$ thickness for all tests and the $700 \mathrm{~mm}$ length mid section thickness was varied to obtain different theoretical shakedown loads. 


\section{Calculation of Shakedown limit}

\section{$5.1 \quad$ General}

The shakedown theorem due to Melan [8] as presented by Maier [7], described the main limitations of the classical theory as:

“(a) Inviscid perfectly-plastic (non-hardening) laws govern the local deformability, and involve convex yield surfaces, associative flow rules and constant elastic moduli (the term inviscid rules out time-effects, such as creep and rate-sensitivity); (b) geometric changes do not significantly affect the equilibrium relations; (c) temperature changes have negligible influence on the material properties; (d) external agencies act so slowly that the system behaves in a quasistatic way (with negligible inertia and viscous forces); (e) adaptation guarantees the survival of the structure, i.e., rules out structural crises by excessive deformation or local failure." The question of the validity of the shakedown theorems for materials with non-associated flow rules has been examined by Maier [7]. He showed that the bounds given by Koiter's theorem are still upper bounds to the shakedown load, even though the real material has a non-associated flow rule.

Melan's theorem can be used to obtain a lower bound to the shakedown limit for a nonstandard material, but the yield-surface must be replaced by a "potential surface" which lies inside the yield surface.

Sharp and Booker [14] applied the linear programming technique adopted by Maier [7]. They assumed a plane strain model with a trapezoidal pressure distribution under a roller. The material of the half space was assumed to be isotropic and homogeneous and the resulting permanent deformation and residual stress distribution were assumed independent of horizontal distance and dependent on the depth. The tangential shear load was taken as a trapezoidal distribution.

The failure criterion used was Mohr-Coulomb and the material properties were assumed to be linear elastic - perfectly plastic.

Melan's static shakedown theorem (lower bound) states that "if any time-independent distribution of residual stresses can be found which, together with the elastic stresses due to the load, constitutes a system of stresses within the elastic limit, then the system will shakedown". In other words, the elastic stresses associated with the maximum load, together with any distribution of residual stress, which just touches the yield surface will give a lower bound to the shakedown limit.

Calculation of Shakedown limits for the various pavement configurations tested in this

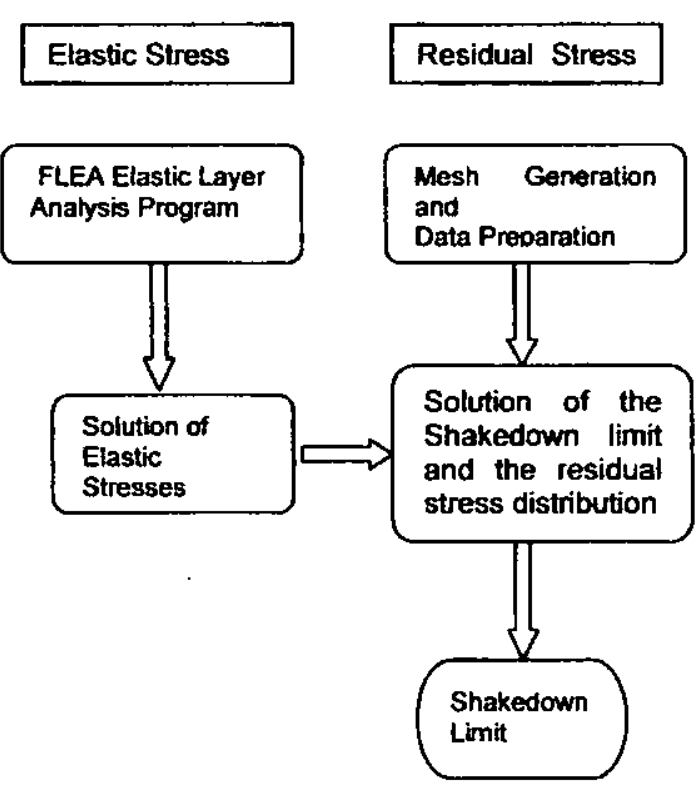

Figure 2- Calculation of shakedown limit

experiment is based on the lower bound calculation procedure indicated in Figure 2.

This procedure assumes that both elastic stresses and residual stresses required by the lower bound shakedown analysis are linearly distributed across the continua and the resulting deformation is plane strain by replacing the wheel load as an infinitely wide roller. A trapezoidal load distribution was selected as the contact load distribution. Stand alone windows based computer software package was developed to calculate the shakedown limit for this experiment. Output from Sydney University's FLEA (Finite Layer Elastic Analysis) program was directly read to provide the elastic stress distributions in the continua and the residual stress field was determined using the linear residual stress finite elements as indicated in Shiau [16] in his $\mathrm{PhD}$ thesis. The Active Set Linear programming technique indicated by Best and Ritter [1] and Sloan [17] and [18] was used to calculate the optimum shakedown limit.

The shakedown factor is defined as $\lambda$ where

$$
\sigma^{t}=\lambda \sigma^{e}+\sigma^{r}
$$


and $\sigma^{t}, \sigma^{e}$, and $\sigma^{r}$ are the total, elastic and residual stresses in the pavement. It is the factor that the elastic stress field has to be multiplied by to keep the total stresses below the (MohrCoulomb) failure criterion. The calculated shakedown limits for the test pavements of $50 \mathrm{~mm}$ and $200 \mathrm{~mm}$ thickness for the wheel load at $80 \mathrm{~N}\left(44 \mathrm{kN} / \mathrm{M}^{2}\right)$ were 0.82 and 1.9 respectively. Elastic Moduli for recycled base material and sand sub grade were used as $350,000 \mathrm{kPa}$ and 200,000 kPa respectively.

\section{Results and Discussion}

\subsection{Database}

Data acquired was comprised of subsurface pavement settlement data from LVDT's, the time of reading, the lateral location of the wheel (as the wheel can be moved laterally relative to the pavement), number of test cycles, spring load monitoring data, subsurface permanent deformation details and transducer calibration data. Results were written to a relational database enabling online analysis and processing (OLAP) of test data.

Results indicate that larger deformations occur for fewer load cycles when the wheel load is more than the shakedown load.

\subsection{Test Results}

Vertical surface deformation (VSD) of the pavement surface was measured at 9 cross sections initially. The number of cross sections was increased to cover the progression of VSD and to produce 3D mesh images of the pavement surface. This made it possible to visualize the settlement pattern of the total pavement rather than individual cross sections. Standard measures such as pavement rutting and roughness are related to VSD but do not have the same degree of reliability. Usually rutting is determined by calculating or measuring the depth of a rut from a straight edge placed across the wheel path and is affected by any heaving at the edges.

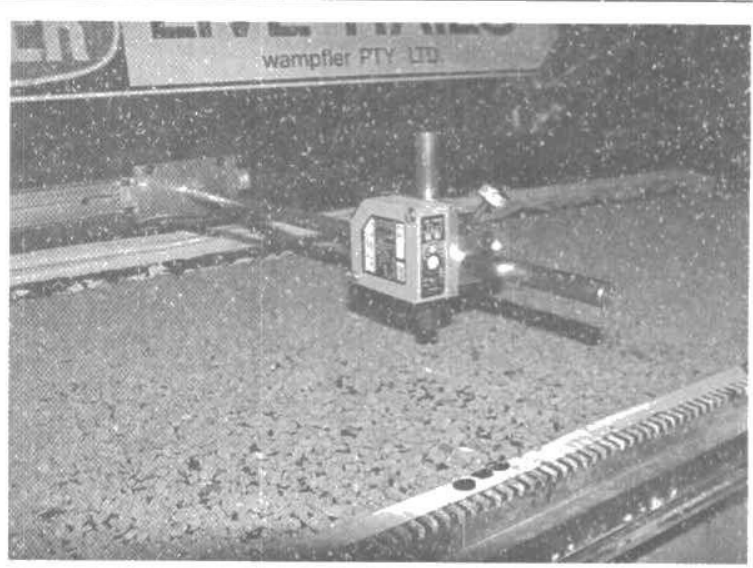

Figure 3- Vertical surface deformation measurement with laser transducer.

Roughness represents the variation of VSD along the wheel path. Results obtained by this

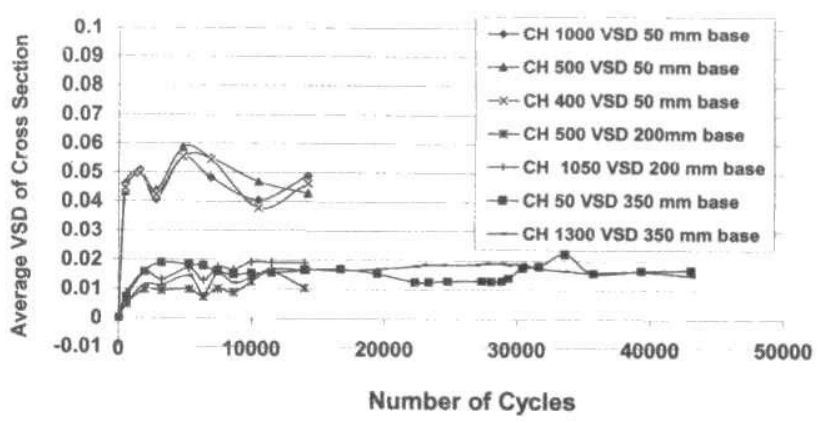

Figure 4- Average VSD (laser reading) of the particular cross section plotted against number of cycles

experiment indicated that there was a rapid increase in VSD in the case of wheel loads more than the shakedown load calculated by the two dimensional shakedown load for the test pavement (see Figure 4). In these tests, trafficking was terminated when the pavement reached a shakedown state or when VSD increased more than $10 \mathrm{~mm}$ in a particular cross section (this corresponds to a $40 \mathrm{~mm}$ depth in the prototype). More tests are needed to verify the long term behavior of the pavement.

Pavement tests with the University of Sydney Pavement Testing Facility have indicated that the shakedown limits predicted by 2-D shakedown theory analyses are a good indicator of whether a pavement will undergo continued deformation under cyclic wheel loading. 


\section{Application of Shakedown Method}

\subsection{Network Level Application}

Current methods of pavement performance prediction depend on traffic loadings, (increment in analysis year by damage functions), surface distress (increment in analysis year by mode: cracking, ravelling, potholes, and rut depth by pavement type classification by probability) and surface roughness (increment in year by components: traffic, surface distress, age/environment). Elastic or plastic behaviour of a road pavement under repeated loading condition will depend on its shakedown parameters.

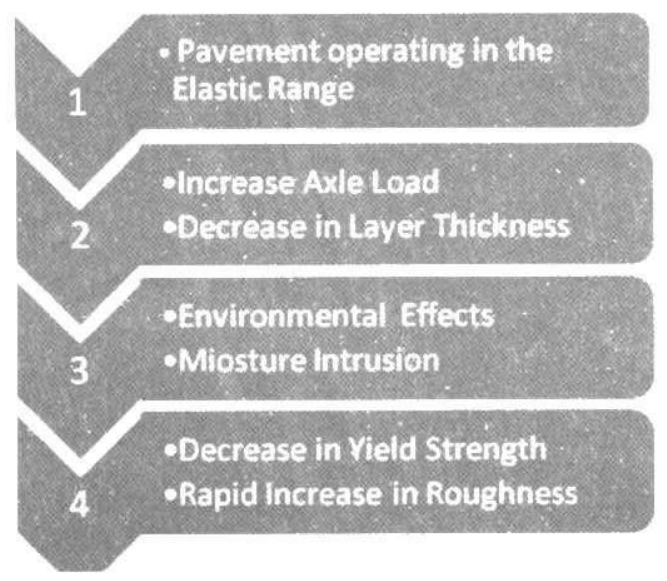

Once initiated, cracking extends in area, increases in intensity (closer spacing) and increases in severity (or width of crack) to the point where spalling and ultimately potholes develop. Open cracks on the surface and poorly maintained drainage systems allow excess water to enter the pavement, speeding up the process of disintegration, reducing the shear strength of unbound materials (lowering the yield limit of the material) and thus increasing the rate of deformation under the stresses induced by traffic loading. Depending on the shakedown state, a pavement may move into a state of "alternating plasticity" or "ratcheting". The cumulative deformation throughout the pavement appears in the wheel paths as ruts and more generally on the surface as an unevenness or distortion of the profile termed roughness.

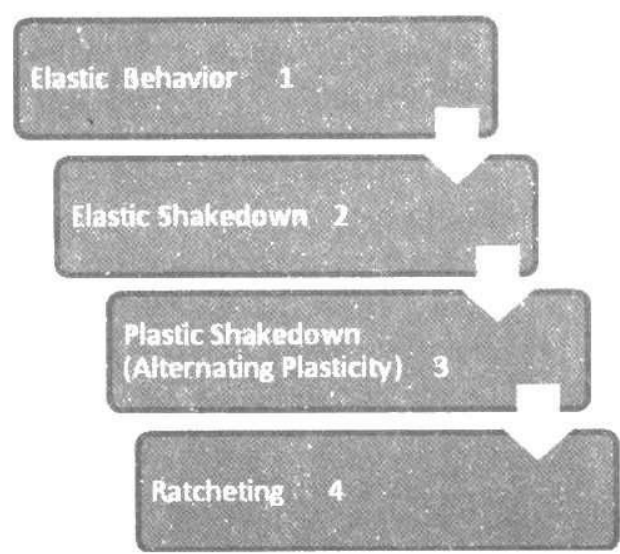

Figure 5 - Various shakedown states of a pavement

\subsection{Pavement distress parameters}

Road pavements deteriorate over time under the combined effects of traffic and weather. Traffic axle loads induce levels of stress and strain within the pavement which are functions of elastic properties of pavement materials and layer thicknesses. Under repeated loading, a pavement will build up residual stresses and shakedown depending on material yield condition and the magnitude of the applied traffic loading. This may proceed to rapid accrual of permanent deformation of all materials or initiation of cracking through fatigue depending on the shakedown state. Weathering causes bituminous surfacing material to oxidize, become brittle and more susceptible to cracking and to disintegrate. This may initiate ravelling, spalling, and edgebreaking.
7.3 Pavement service life - network level application

Remaining service life of a road pavement is an important parameter on which the road network pavement level asset manager or the project level pavement design engineer considers asset management or pavement rehabilitation solutions. Long term future funding arrangements, estimation of road asset depreciation and project level intervention options are very much depend upon this parameter.

Pavement service life can be defined as the cumulative traffic loading, expressed in ESAs, (Equivalent Standard Axles) from the immediate post construction or rehabilitation/replacement condition to a predetermined threshold value of a range of distresses beyond which the pavement is no longer acceptable for use. Similarly pavement 
service traffic can be defined as the cumulative traffic loading, expressed in ESAs, from the immediate post construction or rehabilitation/replacement condition to a predetermined threshold value of a range of distresses beyond which the pavement is no longer acceptable for use.

Current remaining life assessment methods could be broadly categorised into functional failure based methods and structural failure based approaches. Former includes roughness measurements, pavement condition index assessments and pavement surface texture depth measurements. Later includes pavement deflections measurements (FWD and deflectograph) and adjusted structural number based approaches Paterson [11].

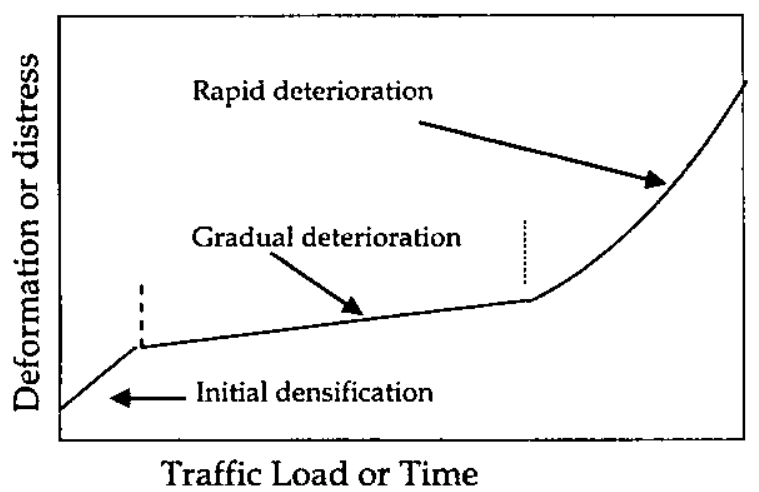

Figure 6- Phases of granular pavement deterioration

Shakedown limit of a road pavement determines whether the pavement will move into a state of rapid accumulation of permanent deformation for a given wheel load. Following Figure 7 indicate the relationship of the shakedown limit to the pavement service life.

The pavement parameters selected were as in Sharp and Booker [13] Tables 8.3 and 8.4 are indicated in Table 3.

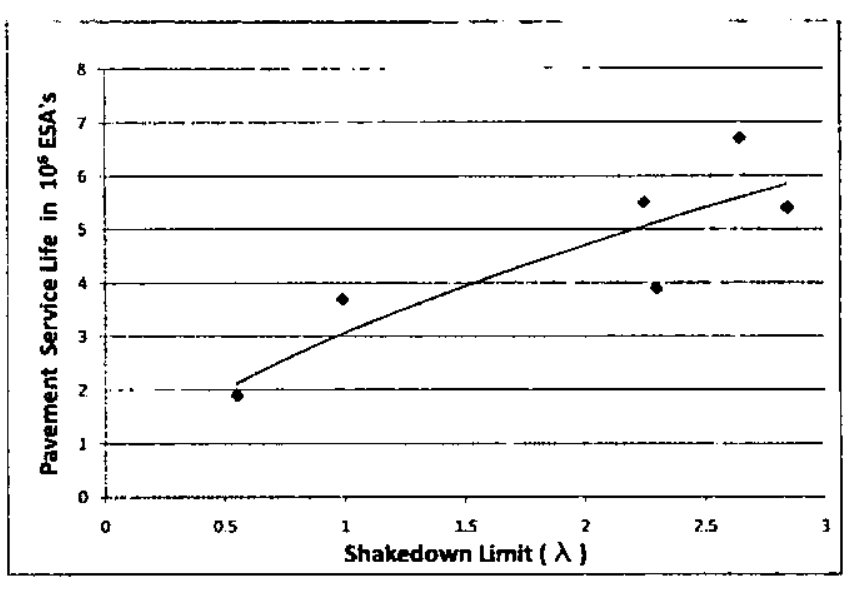

Figure 7- Pavement Service Life (ESA) plotted against calculated Shakedown Limit of the pavement

Table 4- Pavement Parameters from (Sharp and Booker, 1983).

\begin{tabular}{|l|l|l|l|l|l|l|}
\hline Road & $\begin{array}{c}\text { Pave. } \\
\text { Layers } \\
\text { Base(M) } \\
\text { Sub- } \\
\text { Base(M) }\end{array}$ & $\mathrm{E}(\mathrm{kPa})$ & $v$ & $\begin{array}{c}\mathrm{C} \\
\mathrm{kPa}\end{array}$ & $\emptyset^{0}$ & $\begin{array}{c}\text { Life } \\
\text { (ESA) } \\
\times 10^{6}\end{array}$ \\
\hline F4 Free & 0.12 & 225000 & 0.4 & 600 & 25 & 6.7 \\
Way & 0.15 & 61000 & 0.3 & 65 & 51 & \\
\hline Windsor & 0.15 & 302000 & 0.4 & 900 & 38 & 5.4 \\
CastleHill & 0.32 & 33000 & 0.3 & 108 & 37 & \\
\hline Windsor & 0.075 & 882000 & 0.4 & 3000 & 35 & 3.7 \\
Kellyville & 0.125 & 39000 & 0.3 & 25 & 48 & \\
\hline Old & 0.15 & 500000 & 0.4 & 1600 & 40 & 1.9 \\
Windsor & 0.2 & 75000 & 0.3 & 75 & 54 & \\
\hline Kissing & 0.19 & 400000 & 0.4 & 700 & 30 & 5.5 \\
Point & 0.15 & 75000 & 0.3 & 79 & 49 & \\
\hline Rock & 0.15 & 287000 & 0.4 & 850 & 33 & 3.9 \\
Wood & 0.1 & 64000 & 0.3 & 80 & 50 & \\
\hline
\end{tabular}

\subsection{Project Level Application}

The writer was involved with a major highway rehabilitation project with the National Highways Authority of India (NHAI) as the Pavement Specialist with Halcrow Ltd UK. The Government of India has embarked on a staged upgrading program of various National Highway $(\mathrm{NH})$ corridors of the Golden Quadrangle, linking the four major metropolitan cities, Delhi, Bombay, Chennai and Kolkata. NH 2 is the link between Delhi and Kolkata. The National Highway Authority of India has been established to carry out this program.

The widening and upgrading of NH 2 is being carried out under several packages. Package IX A relates to the 2 lane section of $\mathrm{NH} 2$ from 
Panagarh $(515 \mathrm{~km})$ to Palsit $(581 \mathrm{~km})$, West Bengal. This section passes through the district capital, Bardhaman and a few smaller urban centres, i.e. Bud Bud, Galsi and Shaktigarh.

On a Build Operate and Transfer (B.O.T.) basis which was privately funded, the Panagarh Palsit (Annuity) Project was located within the Bardhaman district of West Bengal. Panagarh and Palsit are situated about $167 \mathrm{~km}$ and 100 $\mathrm{km}$ north-west of Calcutta respectively. The project road also serves as a link between Kolkata to the north east part of India.

\subsection{The state of elastic shakedown}

About 3 to 4 months after construction up to the Dense Bituminous Macadam (DBM) surface level in Panagarh - Galsi section of the project, extensive rutting and flushing of the DBM surface was observed during its first summer season. Through traffic was diverted to the two right hand lanes at the time to cater for the construction of the left hand two lanes. The right hand two lanes had DBM layers completed. An investigation was launched in April 2004 to ascertain the causes of rutting.

Rutting initiated during the inter monsoon period from May 2004 to June 2004. Rutting increased during the rainy season (June to August) and reached a stable configuration nearly one month after the rainy season ended (October). After an extensive investigation, it was established that during various stages in the construction process, moisture intrusion into the unbound pavement layers underneath the DBM layer as the main cause for this settlement. (Ravindra [12]).

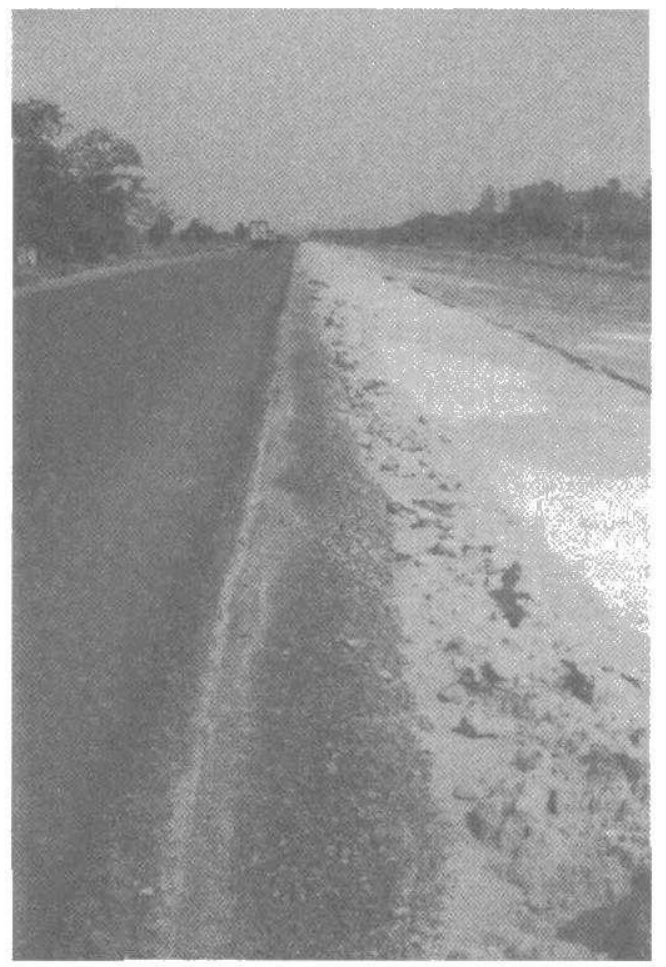

Figure 8 - Open median and the unsealed Wet Mixed Macadam (WMM) edge underneath the Dense Bitumen Macadam (DBM) layers (note moisture intrusion after a storm)

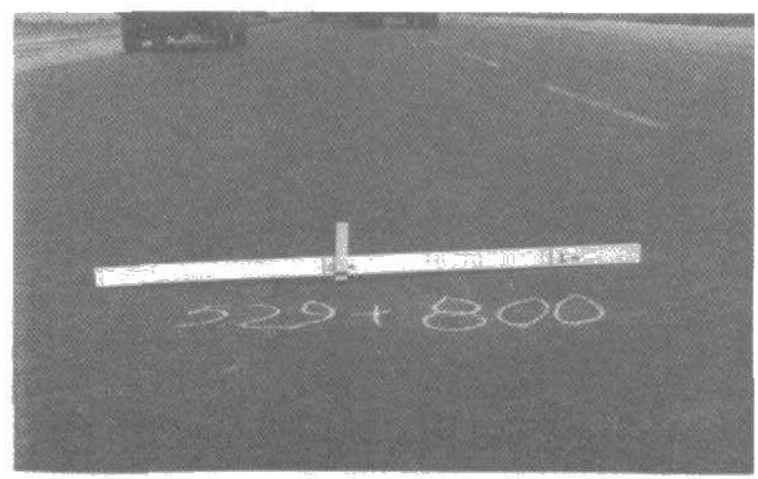

Figure 9- Rutting in main carriageway

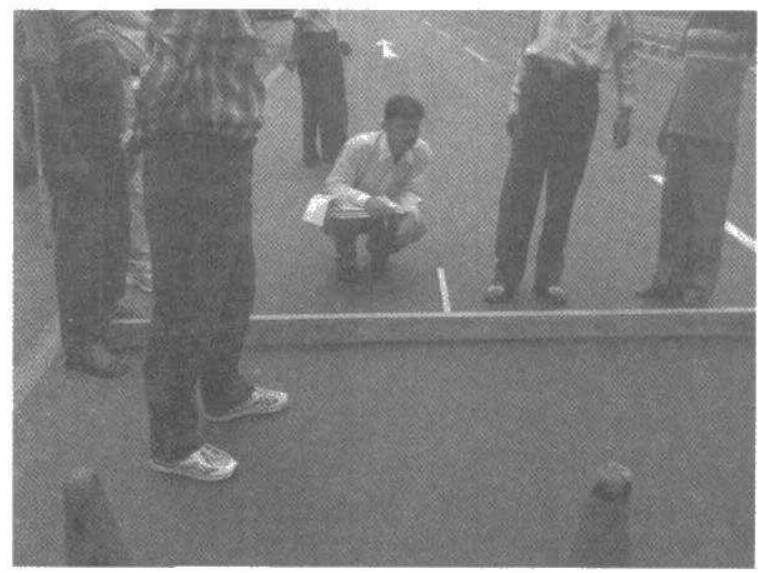

Figure 10- Rut depth monitoring program 
Monitoring of rut depths continued until November 2004 after first being identified in April 2004. Figure 11 indicates various rut depth measurements at locations selected by the Independent Engineers staff. Individual clusters show their gradual development and how these depths settle down to a stable configuration during the passage through the rainy season.

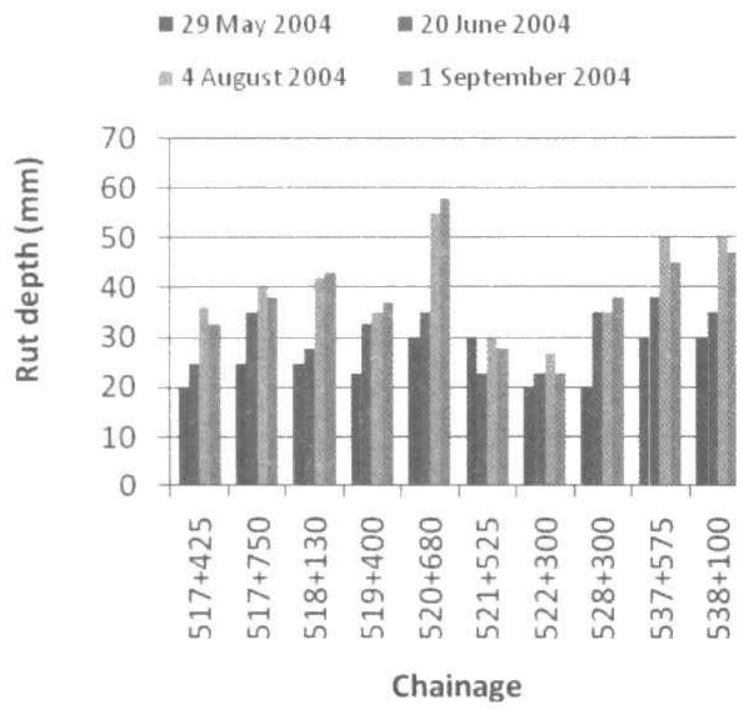

Figure 11- Rut depth development

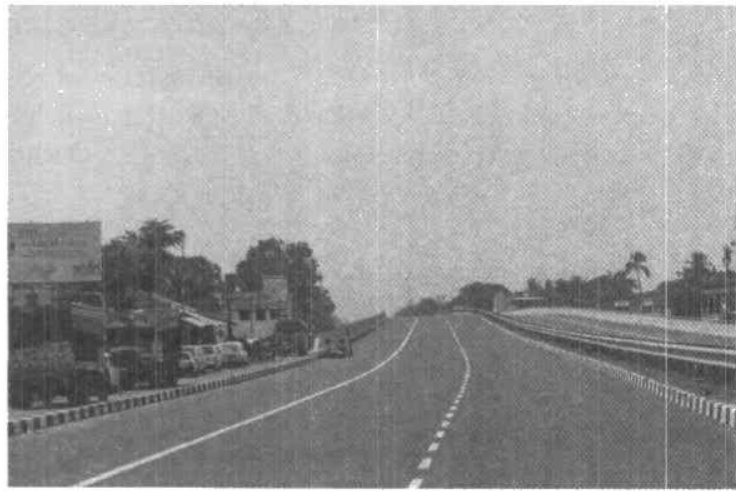

Figure 12 - Typical completed over-pass crossing with service roads either side.

\subsection{The state of rapid failure}

Along the same Highway at all village centers and at cross-roads, overpasses were provided to the public. Service roads connected the highway to the village centre. Pavement thicknesses are given in Table 5.

During construction of these overpasses the concessionaire (owner in a BOT type construction project) used sand as a fill material for the overpass embankments. Also during construction, through traffic was diverted through the service roads. Water saturation was used as a means of compacting the dry sand as shown in Figure 13.

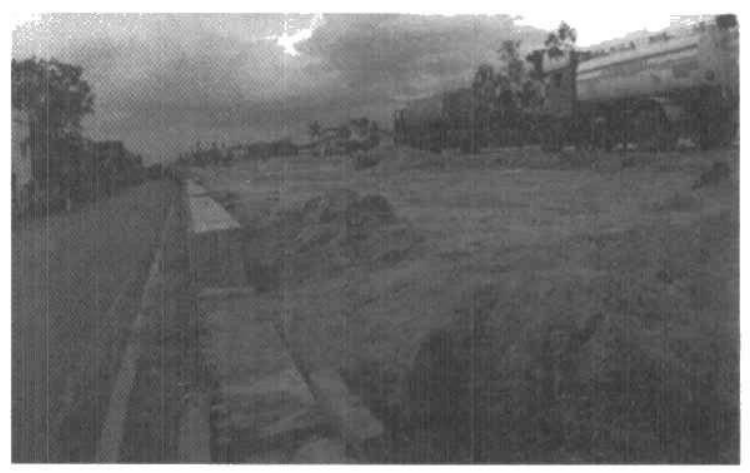

Figure 13- Saturation of the main over-pass sand embankment as a means of compaction.

Saturation of the sand embankment had an immediate effect on the moisture saturation levels in the unbound pavement layers of the service roads.

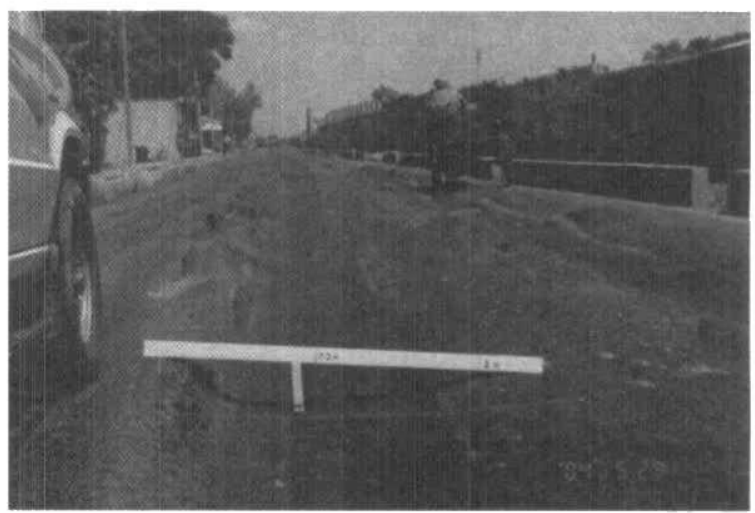

Figure 14- Further deterioration of service roads (6 weeks after initial corrugation).

Further deterioration occurred under through traffic and most of the dense bituminous macadam layer collapsed after approximately 6 weeks. This stage of the road failure could be classified as rapid failure due to "Ratcheting" (see Figure 14).

\subsection{Comparison of shakedown limits}

Table 5 indicates the calculated shakedown limits for both pavements using assumed material parameters. Assumed material parameters were: elastic modulus of DBM layer ( $500000 \mathrm{kPa})$, elastic modulus of unbound material ( $200000 \mathrm{kPa})$, wheel load $(500 \mathrm{kPa})$, cohesion of asphalt layer $(65 \mathrm{kPa})$, cohesion of unbound material (55 kPa) (before saturation including lateritic gravel)), undrained cohesion of unbound material (5 $\mathrm{kPa})$, angle of internal 
friction of the unbound material $\left(30^{\circ}\right)$, undrained angle of internal friction of the unbound material $\left(1^{\circ}\right)$, angle of internal friction of the DBM layer $\left(46^{\circ}\right)$, density of asphalt layer $\left(21 \mathrm{kN} / \mathrm{m}^{3}\right)$ and density of unbound material $\left(17 \mathrm{kN} / \mathrm{m}^{3}\right)$

Calculated shakedown limits showed that main carriageway has shaken down to a stable elastic response state whilst the service roads moved to an incremental collapse state "racheting". Main carriage way was repaired with a corrective asphalt layer and continued with the asphalt concrete wearing course. Service roads were rebuilt after the constructions of the sand embankments were completed. Information from the site indicated that 4 years after the opening to traffic particular main carriageway sections performed well.

Table 5 - Calculated Shakedown limits

\begin{tabular}{|c|c|c|}
\hline & Main Carriage Way & $\begin{array}{l}\text { Service } \\
\text { Road }\end{array}$ \\
\hline $\begin{array}{l}\text { Asphaltic } \\
\text { Material }\end{array}$ & $\begin{array}{l}50 \mathrm{~mm} \text { Asphalt } \\
\text { Concrete (AC) } \\
150 \mathrm{~mm} \text { Dense } \\
\text { Bituminous Macadam } \\
(\mathrm{DBM})\end{array}$ & $\begin{array}{l}40 \mathrm{~mm} \\
(\mathrm{AC})\end{array}$ \\
\hline $\begin{array}{l}\text { Unbound } \\
\text { Material }\end{array}$ & $\begin{array}{l}250 \text { Wet Mixed } \\
\text { Macadam (WMM) } \\
200 \text { Granular Sub Base } \\
1 \text { (GSB1) } \\
150 \text { Granular Sub Base } \\
2 \text { (GSB2) }\end{array}$ & $\begin{array}{l}150 \mathrm{~mm} \\
(\mathrm{WMM})\end{array}$ \\
\hline $\begin{array}{l}\text { Shakedown } \\
\text { Limit }\end{array}$ & 1.26 & $\begin{array}{l}0.79 \\
\text { (using } \\
\text { drained } \\
\text { strength) }\end{array}$ \\
\hline
\end{tabular}

\section{Conclusions}

Preliminary testing of pavements with the University of Sydney Pavement Testing Facility have indicated that the shakedown limits predicted by $2-\mathrm{D}$ shakedown theory analyses are a good indicator to see whether a pavement will undergo continued deformation under cyclic wheel loading. Shakedown limits predicted appear to correlate with the long term the pavement performance which is an indicator to see pavement service life at the network level. Also shakedown limit is a good indicator of whether a pavement will undergo continued deformation or settle down to an elastic response state, could be used at the project level.

\section{References}

1 Best, M.J. and Ritter, K., Linear Programming: Active Set Analysis and Computer Programs, Prentice-Hall, New Jersey, 1985.

2 Bleich, H., “Über die Bemessung statisch unbestimmeter Stahlwerke unter der Berücksichtigung des elastich-plastischen Verhaltens des Baustoffes", Bauingenieur 13 1932, pp. 261-267.

3 Grüning, M., "Die Tragfähigkeit statisch unbestimmter Tragwerke aus Stahl bei beliebig haüfig wiederholter Belastung", Springer, Berlin 1926.

Hossain, M.Z. and Yu, H.S., Shakedown analysis of multi layer pavements using finite element and linear programming. Proc. 7 th Australia-New Zealand Conference on Geomechanics, Adelaide: 512-520, 1996.

Koiter, W.T., General Theorem for ElasticPlastic Solids, In: Progress in Solid Mechanics, Eds. Sneddon, J.N. and Hill, R.,1, North Holland, Amesterdam, The Netherlands:165221, 1960.

6 König, J.A., "Shakedown of Elastic-Plastic Structures", Elsevier Science Publishers, Amsterdam, The Netherlands, 1987.

Maier, G., Shakedown theory in perfect elastoplasticity with associated and nonassociated flow-laws: A finite element, linear programming approach, Meccanica 4: 250-260, 1969. 
Melan, E., Theorie statisch unbestimmer Systeme, Prelim. Publ. 2nd Congress of International Association of Bridge and Structure Engineering, Berlin, 43, 1936.

9 Melan, E., "Der Spannungszustand eines Mises-Henckyschen Kontinuums Bei Verändlichen Belastung.", Sitz. Ber. Akad. Wiss. Wien, Abt. ha, Vol.147, pp.73-87, 1936.

10 Moghaddas-Nejad, F. and Small, J.C. , Effect of Geogrid Reinforcement in Model Track Tests on Pavements, Journal of Transportation Engineering 127(6): 468-474, 1996.

11 Paterson W. D. O., Road deterioration and maintenance effects. Models for planning and management. The International Bank for Reconstruction and Development, Washington, DC, USA, 1996.

12 Ravindra, P.S., Shakedown Analysis of Road Pavements - An Experimental Point of View, PhD Thesis, University of Sydney, January 2009.

13 Sharp, R.W. and Booker, J.R., Shakedown Analysis and Design of Pavements, $P h D$ Thesis, University of Sydney, April 1983.

14 Sharp, R.W. and Booker, J.R., Shakedown of Pavements under moving surface loads, Journal of Transportation Engineering, ASCE110(1): 1-14, 1984.

15 Shiau, S.H and Yu, H.S., Shakedown analysis of flexible pavements, Developments in Theoretical Geomechanics: Eds. Smith \& Cater, Balkema, 2000.

Shiau, S.H., Numerical Methods for Shakedown Analysis of Pavements under Moving Loads, $P h D$ thesis, University of Newcastle, Australia, 2001.

17 Sloan, S.W., Lower bound limits analysis using finite element and linear programming, International Journal for Numerical Methods in Geomechanics 12: 61-67, 1988a.

18 Sloan, S.W. A steepest edge active set algorithm for solving sparse linear programming problems, International journal for Numerical Methods in Engineering 26: 2671$2685,1988 \mathrm{~b}$.

Werkmeister, S., "Permanent deformation behaviour of unbound granular materials," $\mathrm{PhD}$ Thesis, University of Technology Dresden, Germany, 2003.

Wong, H.K.W. and Small, J.C., Effect of Orientation of Approach Slabs on Pavement Deformation, Journal of Transportation Engineering 120(4): 590-602, 1994.
21 Yu H.S. and Hossain M.Z.. "Lower bound shakedown analysis of layered pavements using discontinuous stress fields", Computer Methods in Applied Mechanics and Engineering, Vol. 167, pp. 209-222, 1998. 